\title{
Strategy in Generative Planning of Turning Processes
}

\author{
F. J. M. van Houten (2). Twente University of Technology/Netherlands - Submitted by H. J. J. Kals (1)
}

SUMYARY

This paper reports on the process and operations planning system KouND and the strategies which underlie the decision making processes in the planning of turning operations. At first, an out line is given about the environnent for which generative systems like ROLND are being developed. The dffferences between high volume production and job shop production, with respect to flexibility and productivity, are designated. The impact of automation on job shop production and its consequences for process and operations planning are discussed. In small batch manufacturing systens, relatively large amounts of process planning data have to be processed, which leacls to an increasing interest for sophisticated computer aided process planning tools. Because available XC part programing systems usually do not support the generation of reliable and econoaic technological data, it is necessary to develop generative process and operation planning systems. Due to the relative complexity of the technological models, generative systems use a lot of computing power. keduction of possible variants, complexity of the technological models, generative systems use a lot of computing power. Keduction of possible variants, combined with mocel refinement are techniques which are used in ROUND, in order to avoid excessive iteration. This is
illustraced by the explanation of strategies which are implemented in two newly developed modules: The clamping module RNDFIX and the module for selection of tools for the roughing operation KNidRTL.

\section{INTRODUCTIO:}

Today, two important market trends, related to industria products, are a steady decrease of product life cycles and growing demand for shorter delivery times. In order to keep up with these developments it is necessary to reduce stocks and vork-in-progress, in order to improve short term delivery and to reduce cost. This apparent contradiction can only be solved by combination of high productivity and flexibility. However productivity and flexibility traditionally are found to be mutually exclusive. The high productive flow-type, high-volume manufacturing systems, usually are rather rigid. In order to manufacturing systems, usually arc rather rigid. In order to lined up along a transport system, while machining operations are carried out in a fixed sequential order. The product mix is ver limited and known on beforehand. The process and operations planning usually is carried out during the design slage of the manufacturing system and is primarily directed towards the efficiency of the machining operations. Pre-production series are run in order to test and tune the different stations in the system. Limited buffers are available to meet temporary interruptions and to compensate for drop-outs. with respect to production control the continuity of inaterial flok is emphasized. Modification of the product is very much restricted emphasized. Modification of the product is very much

Typical job-shop type Elexible systems show a rather low productivity. In order to be able to produce a wide and unpredicrable variety of products, general purpose machine tools are manned by skilled operators and usually are grouped according to type (function). Transport of products is not very sophisticated and severe routed problems exist because the sophisticated and severe routeing problens exist because the
sequence of operations can be different for every different product. Part and operations planning is a continuous activit which primarily is directed towards the reduction of drop outs and the improvement of the reliability of the operations. In many cases substantial amount of work-in-progress is found on the shop floor, serving as a buffer between subsequent machining operations. Due to this fact the overall production times in this type of system usually are rather high.

Flexible manufacturing automation promises an adequate combination of productivity and flexibility. In mass production, combination of productivity and flexibility. In mass production, flexible way to product changes, while in snall-batch manufacturing it must lower production costs but also significantly reduce overall production times by the reduction of work preparation and set-up times. Ilowever, a considerable difference in productivity level and flexibility will remain between the two different types of automated manufacturing systems. The main reason for this is the large difference in the amount of data per 'unit of product' which has to be handled by the system. In the job-shops this ratio is much higher than in high volume production. On the average, more than seventy percent of all activities consists of data processing. while less than thirty percent is directly related to processing, while less than thirty percent is directly related to automation is not supported by efficient data processing and date comunication, it will not be able to raise the productivity of the job-shop significantly, but it will lower its flexibility drastically. Hence flexible autamation of a job-ghop is substantially more difficult than flexible autosation of highvolume production.

Practically all operational Flexible Manufacturing Systems (FMS) are used in high-volume production. Only very few are able to produce a mix of more than ten different products. From the point of view of traditional high-volume production, this is of course a tremendous improvament in flexibility but it still cakes course a tremendous improvement in flexibility but it still takes
a lot of time and effort to add new products to the mix. Because some of these systems are able to produce products of this mix in an arbitrary sequence, they are often referred to as small-batch production systems. This is in fact confusing because the meaning is different when it is used in relation to a job-shop environment. Although batch sizes may be small in both cases, the frequency of product repetition is high in high-volume production and usually extremely low in job-shop production.

It may be clear that bMS systems, developed for use in high volume production, by no means are fit for use in a job-shop environment. lowever, many job shops already have enough tools. Production problems usually are solved on the spot, by the machine tool operators and hardly any information is fed back to the planning department (if there exists any). In many cases the ratio between productive and non-productive time is not much ratio between productive and non-productive time is not much higher than one to ten. This is mainly caused by set-up-, problems. It is obvious that it is not very sensible to install problems. It is obvious that it is not very sensible to install
complex and expensive Fils when there is no adequate control of information flow.

\section{PKOCLSS AND OPERATIONS PLANNING FOR FIS}

In the past decade the developments in $\mathrm{XC}$-control have been direcled towards better programmability on the shop floor. ialogue input, graphic simulation, complex canned cycles etc. have increased, gre productivity and flexibility of the manmachine system. In this way it has been possible to introduce NCmachine system. In this way it has been possible to introduce. .C-
aachines in conventional workshop enviconments, while avoiding the necessity of radical changes in the organization. CNC has lowered the threshold for the introduction of automation but it hampers the evolution towards more integrated FIS.

The development of FMS for job-shop environments undoubtedly is one of the most challenging areas in the field of production engineering today. However, integration of highly automated manufacturing equipment is a very complicated matter. A lot of manufaccuring equipment is a very complicated matter. A tot of problems have to be solved in order to be able to achieve an acceptable productivity level without lo sing the required communication facilities of CNC controllers and the differences in programing functions, codes and formats [1]. This could be solved by buying a complete turn-key FMS system from one manufacturer, but in most cases existing equiprent has to be integrated.

The most important technological problems are related to set-up design, tool selection and selection of proper machining conditions. Orpanization problems arise in the areas of order planning. scheduling, tool- and waterials magement, cycle-time adjustment, production control etc.

Dne of the prevailing requirements with respect to flexibility in scheduling, for instance, is the freedoro to allocate identical rorkpieces to different machine tools. This requires eitiner variety of machine tool dependent NC-programs to be available beforehand, or the possibility to generate. NC-programs within the time span available between the selection of the machine tool and the actual machining operation. This type of (dynamic) schedulin causes severe problems, in particular when relatively complex

Process and operaitong

Process and operations planning is ane of the key functions in job-shop FiS. The planner is responsible for the distribution of the detailed manufacturing data throughout the system. Because of the fact that all actions and operations are interrelated, uncontrollable interference on the shop floor is not desirable.
This means that flexibility no longer can depend on improvisations on the shop floor but has to be implemented in the preparatory and management functions. This puts a heavy burden on the planning department. The preparation of large amounts of adequate and accurate data within limited time requires sophisticated computer aids.

Yany of the presently available NC-part-programing systems are only dealing with the geanetrical aspects of machining. They are able to calculate cool parths, but need human interaction for the interpretation of product models which are generated by CAD systems or by manual input of conventional drawings. The technological decisions, such as the selection of set-up, tools and machining parameters usually have to be taken in the conventional way, as only very few systems support these functions properly. Some workpiece-programing systems and CXC controllers provide the possibility for storage and retrieval of tool and machining data, but without models to describe the complex relationships between the machining variables and the complex relationships between the machining variables and the 
in an efficient way.

\section{GLiNERATIVE PLANNING SYSTEYS VERSUS MACHIHABILI'ZY DATA baSES}

is every other product is different with respect to batch size work material, shape, volume of material to be removed, added value by previous operations, surface quality etc., it is alnost impossible to retrieve all necessary technological machinine information from a data base, just by trying to find a similar machining situation.

is so many different factors influence the machining process, the use of generalized mathematical models which describe the relationships geres the machining process is the best way to produce reliable and economic IC programs within a limited amount of time. Using generative process and operations planning systems is also the best way to accumulate knowledge about the interdependence of the parameters which control the machining processes. For instance. by providing the possibility to explain to the operator the reasons behind the preference for certain thache tools tools or archining conditions, it becomes possible to detect whether the production system is well cuned to the product mix or not.

Not only knowing 'how' but also knowing 'why' is very important. It is disngerous to accumulate 3 lot of data on machining operations which have been successful in the past without recording how successful they were and under which eircumstances they were successiul. This is the main problem of large machinability data bases.

The problem of generative systems is that the greater part of the data which are needed is of ten not available in the right form and have to be evaluated from measurements on the shop floor, which usually is very laborious. It is much easier to floor, which usually is very laborious. It is much easier to select technological data directly from a general handbook or data base, but it is obvious that this data does not take into
account the constraints and possibilities of the specific situation [2].

\section{STRATEL'Y, FEED FORWARD AND FLEU BACK}

In process and operations planning, decisions, made at early 1n process bally influence decisions to be made in later stages. For instance, when the set-up for the machining of a specif ic For instance, when the set-up for the machining the different workpiece has to be determined, all details about the different machining operations have not yet been calculated. llence it is technical as well as an economical point of vicw. However, a poor set-up can impose too heavy constraints upon the machining conditions and consequently hamper productivity.

On the other hand it is certainly not practical to investigate all possible variants extensively in order to be able to select the best solution. It is not sensible either to repeatedly go back on decisions taken earlier, in order to avoid problems occurring at a later stage. To much feed back within a system of this complexity causes intolerable calculation times and costs.

Following a strategy which is mainly based on a feed forward approach, the need of excessive iteration can be avoided. In this way it is possible to make short cuts and to solve the problem in a limited period of time. Strategies should mainly be based on early elimination of unsuccessful branches in the decision-tree. This ean achieved by using coarse estimation models in the This can be achleved by using coarse es in first stages of the planning process in order to weigh the consequences of selections in terms of times and costs. Convergence through model refinement in the subsequent stages
leaves the possibility for optimization of the individual leaves the possibility for optimization of the individual
machining operations, without excluding the possibility of final adjustments of cycle times for synchronization purposes.

\section{ROUND, A GENERATIVE PLANNING SYSTEM FOR TURNING OPERATIONS}

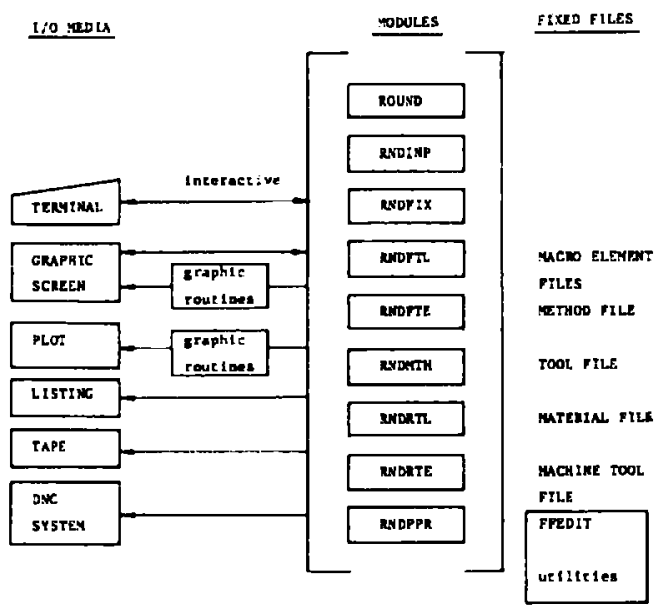

FIG. I THE LAYOUT OF THE SYSTEM ROUND.

ROUND is a generative process and operations planning syster for turning operations, which is being developed in the Laboratory of Production Engineering at Twente University of Technology. The system has been developed starting from a program which calculates economic cutting condicions into a larger system which covers the planning and information processing over the whole trajectory, from part definition to NC machining. A vorking prototype exists.

ROUND is built up out of a number of modules, each of them covering a distinct part of the planning task. The cutting technology module [3] and an overall description of the system technology module [3] and an overall description of the system [4] have previously been reported in CIRP papers. Fig.1 shows a modules which have recently been developed and the underlying strategies will be discussed.

\section{THE CLAMPING YODULE RNDFIX}

A ROUND run starts with the execution of the input module RNDINP [5]. After the part has been specified the digenstons of the blank may be defined. Specification of the blank will only be necessary when it is a casting or when it is pre-shaped necessary when it is a casting or when it is pre-shaped
otherwise. When bar material is to be used, the blank otherwise. When bar material is to be used, the blank
dimensions are determined by the clamping module RNDFIX [6]. The primary task of this module is to determine the sequence of setups.

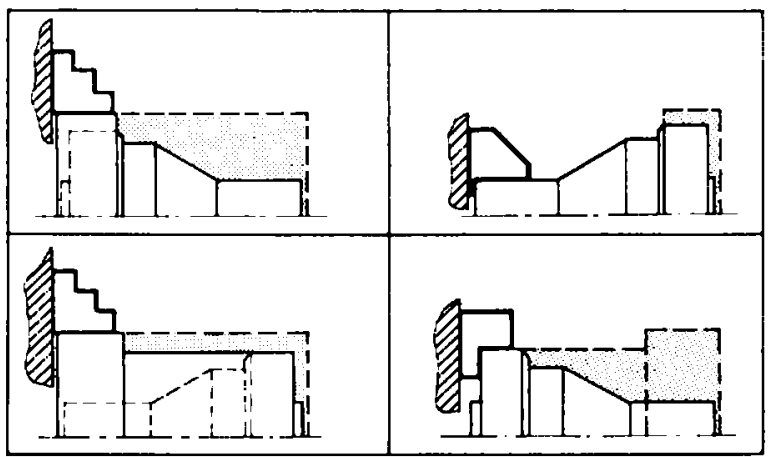

FIG. 2 TWO ALTERNATIVE SOLUTIONS FOR THE MACHINING OF A PART IN TWO SET-LPS.

First the most appropriate machine tool and a number of possible alternatives should be selected from the ones which are available. This selection is based upon criteria like compatibility of workplece dimensions and geometric range of the compatibility of workplece dimensions and geometric range of the power, torque, work material, volume of material to be removed etc. As this part of the module is still under development, autanatic michine tnol selection is not yet available in the prototype version and hence this task has ta be performed by the operator.

After having selected a specific lathe there is only a limited freedom in selecting jigs and fixtures, because exchange or modification of hydraulical chucks and tailstocks is usually not mossible or too much time consuming and costly. It does not pay possible or too much time consuming and costly. It does not pay realistic possibility. Hence the clamping problem is reduced to realistic possibility. Hence the clamping problem is reduced to set-up of chuck and tailstock and in some cases the calculation of the required length of the blank.

If a part can be machined entirely in one set-up, it is very likely that this will be the best solution. Only in those cases where complicated separating operations are required it will be necessary to consider more than one set-up. In the second set-up, a machined surface my have to act as a clamping surface which limits the maximum applicable torque. The combination of work material and required clamping force may compel to the use of soft jaws, which have to be pre-machined to fit the clamping surface exactly. This is necessary in order to avold damage to the part and to assure maximum friction. It yields of course a substantial disadvantage in comparison with machining in one setup. The extra time needed for the exchange of the jaws is also disadvantageous. Within an FMS system complete parts have to be produced one by one so the exchange has to be performed twice for every product.

When the product can be machined in one set-up, but in both possible positions, the most economic set-up has to be selected. If more than one set-up is required, the module has to determine the types of jaus to be used as vell as the location of the clamping surfaces with respect to blank, part and jaws. In addition the module has to calculate the intermediate contour which describe the shape of the product after coapletion of the first set-up. It has to search for that combination of set-ups which satisfies best the optinization criteria, without elaborating all possible variants. Fig. 2 shows two possible solutions for the machining of a part in two consecutive set-ups. The selection strategy is based on determination of feasible clamping surfaces (see Fig. 3) and division of the volume to be clamping surfaces (see Fig. 3) and division

removed into machining areas (see Fig. 4).
Geometrical constraints are imposed by the initial shapes of part and blank; cylindrical clamping surfaces of sufficient 
length have to be available.

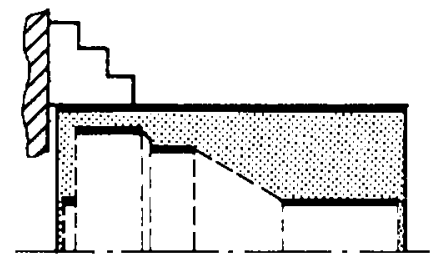

FIG. 3 THE POTENT IAL CLAMPING SURFACES.

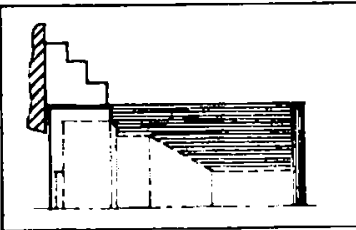

2.: TURKINC

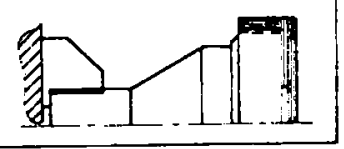

助监国 FACING
FIC. 4 DIVISION OF THE VOLLME TO BE REMOVED INTO YACHINING AREAS.

Technological constraints are imposed by the required geometric accuracy of the part (concentricity, cylindricity, surface roughness, roundness etc.) but also by the required clamping forces in connection with the cutting forces and by inertial forces. The models to calculate the necessary clamping forces and maximum rotational speed are according to VDI 3106 [7]. This ensures the generation of set-ups which meet an accepted safety standard. The potential combinations of solutions are compared by using a cost rodel which can be tuned according to the experience, needs and circumstances of a specific company. Tuning is performed by adjustment of the safery- and balancing- factors. is performed by adjustment of the safety- and balancing- factors. The predicted cost related to the machining of a product in a
spectif ic set-up is a sum of calculable costs and estimated costs. Factors which play a role in the calculable costs are order size batch size, jaw-changing costs, jaw-setting costs, jaw-machining costs etc. The estimated costs are influenced by technologica factors such as the clamping factor, the existence of axial contact between jaw and part and the necessity of grooving operations. The clamping factor is used as a coarse estimation of the relative quality of a combination of set-ups and is defined as:

$$
\mathrm{Kcl}=\frac{\text { vol }}{Z}=\frac{\text { vol }}{A^{*} \mathrm{~V}}
$$

where vol stands for the volume of a particular area which has to be removed in a particular set-up, $Z$ is the metal removal rate. is the cross-section area of the chip and $v$ is the cutting speed. The minimum cutting force $F v$, required to remove a chip with area $A$ is calculated from:

$$
\text { Fv - Es * A }
$$

where Es is the specific cutting energy

The maxisum cutting force is limited by the clamping force fic which can be applied by the chuck and can be calculated from:

$$
F v=F c h /\left(X_{t}+K b\right)
$$

where $\mathrm{Kt}$ is the reduction factor for torsion and $\mathrm{Kb}$ is the reduction factor for bending.

The ratio between the components of the cutting force are estimated according to [11]:

$$
\begin{aligned}
& \text { Ff } / \mathrm{Fv}=0.4 \text { and } F p / F v=0.2 \\
& K t=\frac{K_{\mu}}{\text { ucht }} * \sqrt{\left(\frac{d c}{d c h}\right)^{2}+0.16\left(\frac{\mu c h t}{\mu c h a}\right)^{2}}
\end{aligned}
$$

For lc $>$ deh

lc

$$
1 \mathrm{ch} * 0.67+0.5 * \mu \mathrm{chg} * \mathrm{dch}
$$

For $l c=<d c h$ or with additional supporting aids $K b=0$

where $\mu$ cht is the friction coefficient in tangential direction and $\mu$ cha is the friction coefficient in axial direction, (estimations of these coefficients are found in [7]), $k_{\mu}$ is the safety factor for the friction ( $K \mu>=1.3$ ), dc is the maximum cutting diameter, Ic is the maximum distance between the respective points of application of the cutting force and the clamping force, dch is the clamping diameter and lch is the clamping force, dch is the clamping diameter and lch is the
contact length between jav and workpiece. The influence of the contact length between jav and workp
weight of the workpiece is neglected.

The available clamping force is calculated from:

$$
F c h=\left(\frac{F c h m a x}{K c h}+\operatorname{rcf}\right) * \frac{1}{K c}
$$

and the centrifugal force from:

$$
\operatorname{rcf}=\operatorname{mj} \neq\left(\frac{\mathrm{lch}}{2}+y j\right) *(2 \neq \pi * n)^{2}
$$

where Fchmax is the usximun clamping force which can be applied by the chuck when the rotational speed $n=0$, Keh is the safet factor For the chuck (Kich $>=1.5$ ), K'c is the safety factor for the cutting force ( $\mathrm{Kc}>=1.5$ ), $\mathrm{m}_{\mathrm{j}} \mathrm{j}$ is the mass of the jaws and $y$. is the distance from the center of gravity of the jaws to the clamping surface. The sign of FcE in equation (B) is negative for external clamping and positive for internal clamping.

Substitution of the equotions $(2 . .9)$ in (1) yialds:

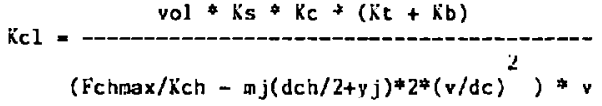

This equation shows a minimum for:

$$
v=\sqrt{\frac{\text { Fchmax } * d c^{2}}{\operatorname{kch} * \operatorname{moj}(d \mathrm{ch} / 2+y j)}}
$$

Sulsticution in (10) yields:

$\mathrm{Kc1}=\mathrm{Ks} * \mathrm{Kc} *\left(\frac{\mathrm{Kch}}{\mathrm{Kch \text {nnax }}}\right)^{3 / 2} * \frac{\mathrm{vol} *(\mathrm{Kt}+\mathrm{Kb}) * \sqrt{6 * \mathrm{mj}(\mathrm{dch} / 2+\mathrm{yj})}}{\mathrm{dc}}$

This factor is useful for comparing potential combinations of set-ups, before all details about the machining operations are known.

The estimated manufacturing costs can be derived from balanced sumation of the clamping factors over all areas and all set-ups.

$$
\operatorname{Ccl}=\sum_{i=1}^{m} \sum_{i=1}^{n}\left(W_{c} * K c 1\right)
$$

where wic is a cost factor thich can be corrected for axial contact, grooving operations etc.

The total cost. per order, in relation with setting up is calculated from:

$$
\left.C=C_{j}+c m * \sum_{j=1}^{m}(t)+t 2\right)+C_{c l}
$$

where $C_{j}$ is the cost related to the machining of sole jows, $\mathrm{cm}$ is the cost of machining time, in is the number of set-ups, $t]$ is the jaw-adjustment time and $t 2$ is the jaw-changing time.

7. THE MODULE FOR SELECTION OF MACHINING TTTHODS FOR ROUGIING OPERATIUNS.

In this module the volume which has to be removed is divided into a number of areas, to each of which a specific machinin operation, such as drilling, turning, facing etc. is assigned. In the prototype version the division in areas has still to be performed by the operator in an interactive way, as this module is still under development.

First, the operator creates the areas to be machined by indicating them on the screen and subsequently assigns machining indicating them on to menu which includes fully specified standard operations. operations without specified direction and operations on grooves operations with

The autonatic version of the module will be able to present the systems ovn sugpestions for division of the area with the matching machining operations. The most economic division is shown first. At choice the operator may call a range of alternatives and select the solution which suits hia best. In other possibility is to rodify manually one of the suggested solutions.

\section{THE SELECTLUN MODULE FOR ROLGHING TOOLS R.VDRTL}

The task of RNDRTL [8] is to select the best tools for machining the areas which are defined by the previous module. The objective is to obtain the most economic roughing tool set for the complete machining process. Selection of the optimun tool for every single area usually will produce a tool set which is far too large in relation to the number of available turret positions and thus will very much complicate tool manaement. The combination of woth effects will lead to a limited, optimal tool set. As a both effects will lead to a limited, optimal tool set. As a
particular tool is selected once its chance to be selected again particular tool is selected once its chance to be selected again
is increased signif icantly because the cost of tool handling and set-up can be shared over more machining operations. 
The problen of finding the optimum set of cools is now split up in two parts:

1) Finding all tools which can machine the respective areas which mainly is a geometrical problen.

2) Selecting the optinum set of tools from it, which mainly is a technological problem.

Due to the differences between roughing and finishing operations the algorichms which have been developed to select finishing tools (KNDFIL) [9] can not be used to select roughing

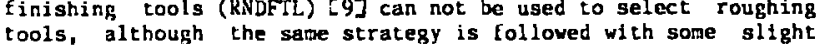
tools, althou
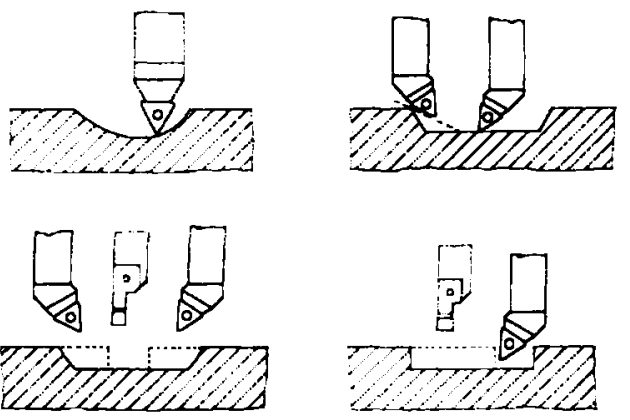

FIC. 5 SOME EXAMPLES OF GROOVING UPERATIONS.

The selection of tools for the machining of grooves and recesses can be rather complicated. If it is not possible to machine the groove with a single tool, a combination of left and right hand tools, neutral tools and grooving tools has to be used. Some examples are shown in Fig. 5. The area of the groove has to be divided into a number of areas, each of which can be machined with a single tool. Usually there are nore solutions, of which the best one has to be selected.

Tool selection is performed in three consecutive steps:

1) Selection on the type of machining operation.

1) Colection on the type of machining operation. (see Fig. 6 and 7 ).

3) Checks for collisions between tool holder and part. As these steps incorporate progressive calculation times, the have to be performed in the given sequence.

When it is alloved to perform roughing and finishing operations with the same tool, the total number of tools-in-use can be reduced. Because tool wear, caused by roughing operations, influences the attainable accuracy and surface roughness during finishing, the decision depends on the required accuracy of the part, the size of the batch and the rules and habits of the part, the

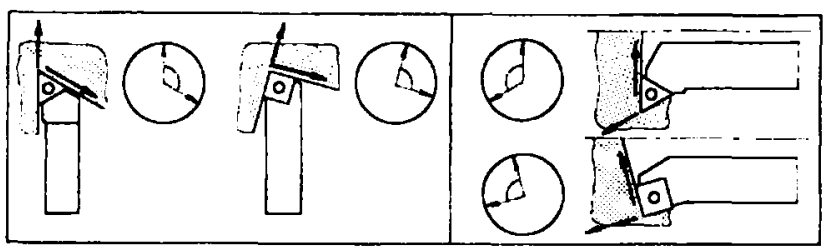

FIG. 6 THF TOOL VECTORS.

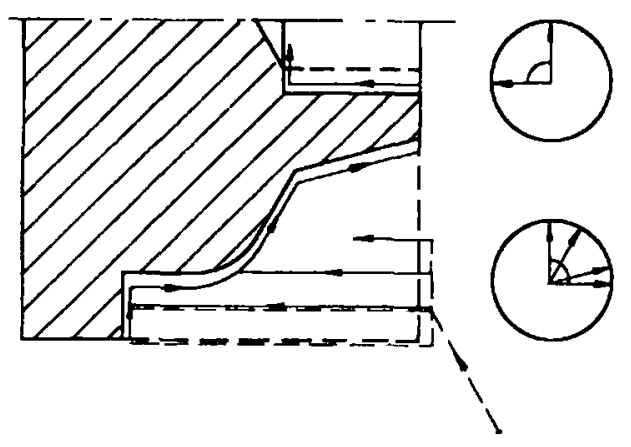

FIG, 7 THE FINISHING CONTOUR ELEMENT VECTORS.

Reduction of the collection of tools which is available to the workshop does not only reduce the amount of invested capital, but also lowers the cost of tool management. An analysis of the frequency of use of the various tool types can help to compose the most sultable basic tool set for every individual machine tool. This minimizes the necessity of tool changes and tool setting and hence increases productivity. The use of block tools, together with autonatic tool changing can be a solution when the number of available turret positions appears to be too small for
nog the basic tool set. When the batch size is smaller than a specified number of products, at first only the tools of the basic tool set are considered for selection. If it is not possible to find a suitable tool for every area, the selection is extended to all other tools in store. The tools selected from the store are exchanged against some tools which belong to the basic tool set but are not used to machine this particular product. The frequency of use decides which tools are exchanged first.

The problem of finding the optimum set of tools is modelled as a thor probs a solved by a dynamic programming technique [10]. network which is is dependent on the arrangement of the colums in the network it is dependent on the arrangement of the colums

is sorted according to the volume of the a

IF in a unidirectional network there are wultiple pachs from node $X(i)$ to adjacent nodes $Y(1 \ldots \pi)$

AND all cost related to those paths are know

AND the optimum route through the network from each of those nodes to the end node is known

THEN the optimum roure from node $X(i)$ to the end node runs vis that specific node $Y(k)$ of which the sum of the costs to get from node $X(i)$ to node $Y(k)$ and the cost of the opt imal route from node $Y(k)$ to the end of the of the optimal route

bach node in the network represents a tool which can machine a specific area and each path represents the selection of a tool for the machining of an area.

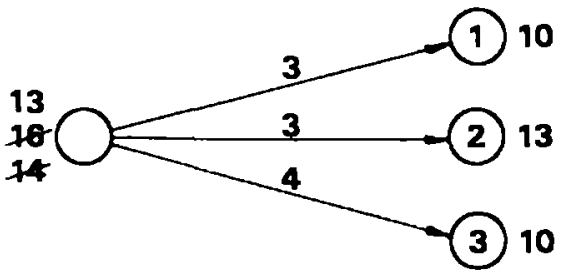

FIG. 8 AN EXAMPLE OF UYNAMIC PROGRAMMING IN A UNI-DIRECTIONAL NETWORK.

The selection of a path involves certain costs. Fig. 8 shoug the explanation of the principle. From the left hand node there are three possible routes to the next nodes. The figures at the right hand side represent the cost of the optimug route from those nodes to the ead node. The figures above the arrows represent the costs to get from the left hand node to the right hand nodes. The smallest sum results from selection of the upper right hand node, so this will be a part of the optiaura route. This principle can be extended throughout the network. The objective function is developed going backwards from the end node (the area with the largest volume), to the starting node. In order to be able to calculate the route with minimal costs, the order to be able to calculate the route with minimal costs, the cost of all paths have to be determined. A rough estimation of these costs will be oufficient at thia stage as the only
objective is to select the proper tools. The actual costs are influenced by the optimization of machining variables, which is the task of the next module RNDRTE [31.

The total costs related to the selection of a particular tool result Erom the sunmation of tool management cost, tool changing cost, machining cost and the cost of the tool. Tool management cost is defined here as: all costs for having the right tool avallable on the right spot at the right moment. When a specific avallable on the right spot at the right moment. When a specific already been selected before, no tool management cost have to be already been selected before, no tool management cost have to
taken into account. Otherwise these cost are calculated from:

$$
\mathrm{Cl}=\mathrm{Ctm} / \mathrm{N}
$$

where Ctm stands for tool management cost and $N$ for the batch size.

The tool-changing costs are composed of the cost for changing the insert due to rool wear and the cost for tool changing due to a limited number of turret positions. In FIS usually block tools will be used and tool changing will be automated. When the tools have to be changed manualig it is very unlikely that a higher have to be changed manualig it is very unlikely that a higher metal removal rate will justify several tool changes per produc

The tool-changing cost can be calculated from:

$$
\mathrm{C} 2=\mathrm{cm} \bullet \mathrm{ts} \bullet(\mathrm{tc} / \mathrm{T}+(2 * \mathrm{~N}-1) / \mathrm{N})
$$

where $\mathrm{cm}$ stands for cost of machining time, ts for tool changing time, tc for actual cutring time, $T$ for tool life and $N$ for batch size. If the number of turret positions is sufficient then $N$ is set to $1 / 2$.

The machining cost are calculated from:

$$
C 3=c m *(t c+L r / v r) \text { with tc }=\operatorname{vol} /\left(s^{*} a^{*} v\right)
$$

where vol stands for the volume which has be renoved, $s$ for the feed, a for the depth of cut, $v$ for the cutting speed, Lr for the total length of all positioning movements, and vr for the speed of rapid feed motion. Lr can be estimated from $\mathrm{L}=\mathrm{A} / \mathrm{a}$, where $A$ is the area of the cross section of the volume to be removed.

The machining variables $a, s$ and $v$ are calculated by using a simplified optimization algorithm, this being of the same 
structure as the one used in RNDRTE [3]. Only the most important constraints are taken into consideration, such as:

- the maximum feed and depth of cut

- the maximum power, torque and rotational speed of the machine tool

- the chip slenderness in connection with chip removal and control.

Within the area created by these constraints, the feed and depth of cut are maximized and the cutting speed is optimized according to the applicable objective function. The algorithm uses approximating formulas and values for the whole machining approximating formulas and values for the whole machining conditions, but usually this effect shows the same tendency for all tools under consideration. In the tool costs only the wear of the insert is accounted for, because the depreciation of the holder is neglectable. It is calculated from:

$$
\mathrm{C} 4=\mathrm{Ct} * \mathrm{tc} / \mathrm{T}
$$

where $\mathrm{Ct}$ stands for the cost of a cutting edge and tool life $\mathrm{T}$ is calculated from the simplified Taylor equation:

$$
T=(K / v)^{(1 / n)}
$$

The sum of the cost related to the use of a particular tool can be calculated from:

$$
\mathrm{C}=\mathrm{X} 1 * \mathrm{Cl}+\mathrm{XI} * \mathrm{C} 2+\mathrm{K} 2 * \mathrm{Cl}+\mathrm{K} 4 * \mathrm{C} 4
$$

where $\mathrm{K1}, \mathrm{X4}$ are balancing factors which can be used to adjust the cost equation in order to influence the selection procedure. When the objective function is miniaum production time $X_{4}$ should be set to zero.

The selection of roughing tools is implemented in such a way that it can be performed fully automatical. However, at choice, the operator can perform manual selection, based on geometric and economic criteria. For instance, it is possible to let the system select all tools which are capable, in a geometrical sense, to perform a specific machining operation, while leaving the final selection of the 'best' tool to the operator. The user interface is menu driven and can supply alpha-numeric and graphic information on the subsequent steps of the selection procedure. information on the subsequent steps of the selection procedure. the network for a simple orachining operation. The cross-hatches the network for a simple machining operation. The cross-hatches

\begin{tabular}{|c|c|c|c|c|}
\hline & 1 & $\begin{array}{c}\text { AREAS - } \\
2\end{array}$ & $\overrightarrow{3}$ & 4 \\
\hline 1 & 11000 & $12012 \#$ & 15000 & 11000 \\
\hline 2 & 11004. & 12020. & 15004. & $11004 . \#$ \\
\hline 3 & 11032. & 23004. & 15004 . & 11032. \\
\hline 4 & 11036. & & & 12036 . \\
\hline 5 & $13000=$ & & & \\
\hline
\end{tabular}
image of a simple part contour with a highlighted machining area and the corresponding tool.

TABLE 1 THE ALPHA-NUGERIC REPRESENTATION OF THE TOOL SELECTION NETWORK

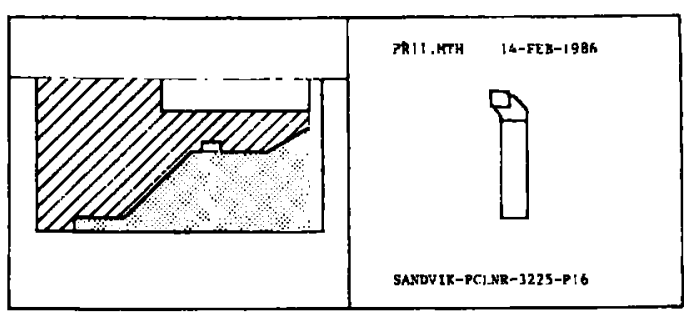

AREA TO BE MACHINE.D WITH THE TOOL SHOWN ON THE RIGHT HAND PART OF THE SCREEN.

FIC. 9 AN EXAMPLE OF A SCREEN IMAGE GENERATED BY RNDRTL

\section{ACKNOWLEDGMENT}

The author wishes to thank G.H. Preuter and T.R. Tysma for their contributions.

\section{REFERENCES.}

1) Houten. F.J.A.M. van, A Machinetool Control and Monitoring System for Flexible Manufacturing Cells, Proceedings of CAPE, Edinburgh (1986).

2) Kals, H.J.J., Houten, F.J.A.M. van, On Flexible Manufacture Based on a Production Information Management System. Proceedings of the 14th CIRP seminar on Manufacturing Systems, Trondheim (1982).
3) Houten, F.J.A.M. van, The development of a Technological Processor as a Part of a Workpiece Programing System Annals of the CIRP, vol. 30,1 , (1981) 363.

4) Houten, F.J.A.M. van, Kals, H.J.J., ROUND a Flexible Technology based Process and Operations PIanning System for

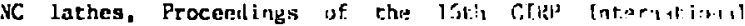

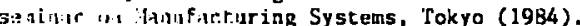

5) Stoltenkamp, H., Houten, F.J.A.S. van, Kals, H.J.J., An Interactive Input-translator for the Programing of Turnins Operations, Proceedings of CAPE' '83, Amsterdam (1983).

6) Tysma, T.R., The Clamping Module in ROUND (in Dutch), University of Technology (1985).

7) VDI 3106, Ermittlung der zulassigen Drehzahl von Drehfuttern, VDI Verlag Gmbil, Duesseldorf (1983).

8) Preuter, 6.H., The selection Module for Roughing Tools in RUUND (in Dutch), Report PT 284, Division of Production Technology, Twente University of Technology (1985).

9) Hinduja, S., Kroeze, B., Selection of Tools for the Finishing Operations on Turned Components, Proceedings of the PROLAilat 85 Conference, Par1s (1935).

10) Wagner, H.M., Princtples of Operations Research, Prentice HaI1, (1975).

11) Bus, c. e.a.. On the Significance of Equivalent Chip Thickness, Innals of the GIRP, Vol. 19, pp.121-124 (1971) 